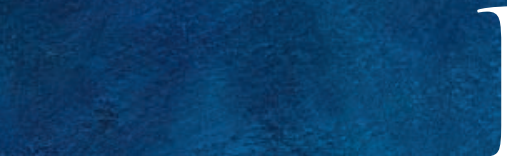

\section{Milestones in the natural course of onset of cigarette use among adolescents}

\author{
André Gervais, Jennifer O'Loughlin, Garbis Meshefedjian, Christina Bancej, Michèle Tremblay
}

$\infty$

See related article page 262

\section{ABstract}

Background: The natural course of onset of cigarette use has been conceptualized as progressing sequentially through 5 stages (preparation, trying, irregular use, regular use, nicotinedependent smoking). However, recent studies suggest that symptoms of nicotine dependence can occur early in the onset process, raising questions about the validity of this model. The objective of our study was to describe the sequence and timing of 12 milestones ( 6 related to cigarette use and 6 to symptoms of nicotine dependence) during onset of cigarette use.

Methods: Grade 7 students in 10 secondary schools in Montréal $(n=1293)$ were followed prospectively every 3-4 months for 5 years. Using Kaplan-Meier analysis, we computed the number of months after first puff at which the cumulative probability of attaining each milestone was $25 \%$, among 311 participants who initiated cigarette use during follow-up.

Results: Inhalation rapidly followed first puff. The cumulative probability of inhalation was $25 \%$ at 1.5 months ( $95 \%$ confidence interval $[\mathrm{Cl}] \mathbf{1 . 5}-\mathbf{2} .5$ ). The cumulative probability (and $95 \% \mathrm{Cl}$ ) was 2.5 months $(1.5-2.5)$ for mental addiction, $2.5(1.0-3.0)$ for smoking a whole cigarette, $4.5\left(2.5^{-8.8)}\right.$ for cravings, 5.4 (3.8-9.7) for physical addiction, 8.8 (7.0-11.9) for monthly smoking, $11.0(6.4-16.8)$ for withdrawal symptoms, $13.0\left(10.3^{-20.5)}\right.$ for tolerance, $19.4\left(14.5^{-31.7)}\right.$ for weekly smoking, 19.5 (14.0-23.9) for lifetime total of $100 \mathrm{cig}$ arettes, 23.1 (19.7-37.6) for daily smoking and 40.6 (35.156.0) for conversion to tobacco dependence.

Interpretation: Symptoms of nicotine dependence develop soon after first puff and can precede monthly, weekly and daily smoking. Cessation interventions that manage dependence symptoms may be needed soon after first puff.

CMAJ 2006;175(3):255-6r

$\mathrm{F}$ ormal evaluations of many prevention programs targeted to youth show little or no long-term impact in preventing cigarette use,,$^{1,2}$ and programs to help young smokers quit have had limited success to date. ${ }^{3,4}$ The lack of sustained impact of tobacco control programs for youth, and the unanticipated reverse effects, ${ }^{5}$ may result from an incomplete understanding of how and why young people initiate smoking. In- creased insight into the early natural course of onset of cigarette use in adolescence may enable the development of more relevant and effective tobacco control programs for youth.

The natural course of smoking onset in adolescence is usually conceptualized as progressing sequentially through distinct stages, beginning with a preparation period, during which interest in smoking is established, and ending with physiologic dependence. ${ }^{6-9}$ Progression from first puff to daily use is thought to take $2-3$ years; progression to nicotine-dependent smoking is thought to take longer..$^{10} \mathrm{How}$ ever, several recent reports ${ }^{11-14}$ suggest that symptoms of nicotine dependence can occur early in the onset process, which raises questions about the validity of this sequential staged model. There is concern that early symptoms of nicotine dependence may contribute to continued smoking.

More studies are needed to describe the early natural course of onset of cigarette use from first puff, in order to characterize milestones such as first time inhaling smoke into the lungs, first time smoking a whole cigarette and first time experiencing symptoms of nicotine dependence. This information could provide stronger underpinnings for better informed tobacco control strategies for youth. The objectives of this analysis were to describe the temporal sequence of attaining selected milestones in the natural course of onset of cigarette use and, more specifically, the time interval between smoking initiation and each of these milestones.

\section{Methods}

The study was approved by the Institutional Review Board of McGill University's Faculty of Medicine, Montréal. Parents of participants provided written informed consent, and participants provided assent. Data were drawn from the McGill University Study on the Natural History of Nicotine Dependence in Teens, a prospective investigation involving 1293 students, recruited from among all grade 7 classes in a convenience sample of io Montréal-area secondary schools. ${ }^{13}$

Baseline data were collected in self-report questionnaires in the fall of 1999, and follow-up data were collected at 3-4 month intervals over the next 5 years. Copies of the study questionnaire are available online in English (Appendix I) and French (Appendix 2) at www.cmaj.ca/cgi/content/full/175 13/255/DCI. About half (55.4\%) of the eligible students participated at baseline. Nonparticipation was due to student re- 
luctance to give a blood sample (for genotyping) and to a provincial labour dispute that resulted in some teachers refusing to collect consent forms. For our analysis, we included only those participants who reported that they had never smoked at baseline and who initiated cigarette smoking in any of the ig follow-up survey cycles.

We used data on lifetime smoking to identify participants who reported at baseline that they had never smoked and who initiated cigarette smoking during follow-up. In each survey cycle, lifetime smoking was measured with the question "Have you ever in your life smoked a cigarette, even just a puff (drag, hit, haul)?" (No; Yes, I or 2 times; Yes, 3 or 4 times; Yes, 5 to Io times; Yes, more than Io times). Among I293 students who participated in the baseline data collection, 8I4 had never smoked (not even a puff). Of these 814,352 $(43.2 \%)$ initiated smoking during follow-up (herein referred to as "initiators"), as measured by any affirmative response to the lifetime smoking question.

On the follow-up questionnaires, participants reported data on cigarette smoking during the 3 months preceding

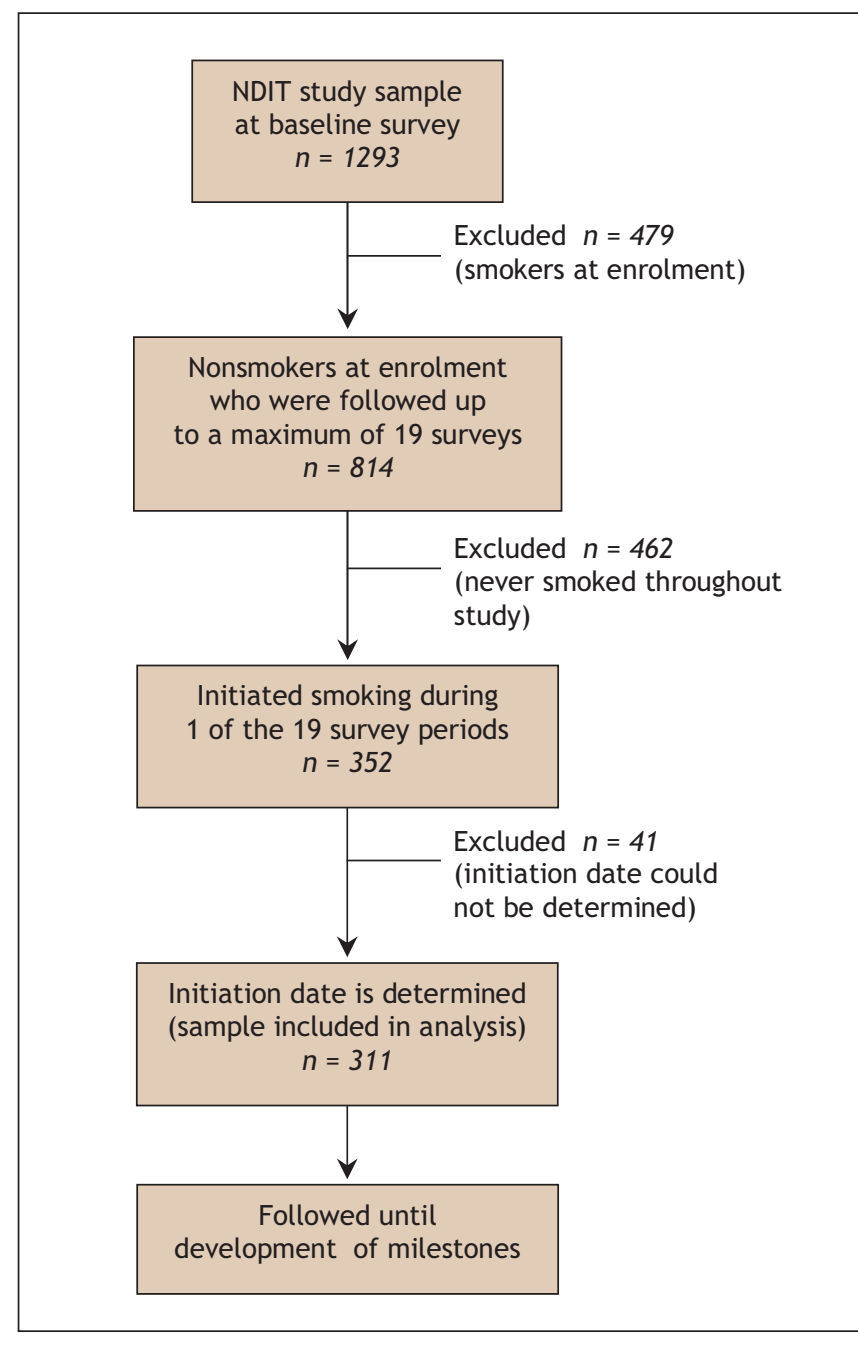

Fig 1: Flow of participants through the study. NDIT = McGill University Study on the Natural History of Nicotine Dependence in Teens. each questionnaire, including the number of days during each month that the subject had smoked and the number of cigarettes smoked per day on average during that month. Three-month test-retest reliability for these 2 items was good (kappa value 0.78 and 0.75 , respectively). ${ }^{15}$ For 253 of the 352 initiators, time (day/month/year) of first puff was designated as the midpoint of the month during which the respondent first reported smoking cigarettes in the 3-month recall. For initiators who did not report smoking cigarettes in the 3month recall, time of first puff was designated as the date of data collection in which lifetime use was first reported ( $n=$ 25) or the midpoint of the year preceding the questionnaire in which they reported smoking in the past year in the selfperceived smoking status item $(n=33)$. Self-perceived smoking status was measured with the item "Check the one box that describes you best" (I have never smoked a cigarette, even just a puff; I have smoked cigarettes, even just a puff, but not at all in the past I2 months; I smoked cigarettes once or a couple of times in the past 12 months; I smoke cigarettes once or a couple of times each month; I smoke cigarettes once or a couple of times each week; I smoke cigarettes every day). A total of $4 \mathrm{I}$ initiators were excluded from the analysis because time of first puff could not be determined, which left $3 \mathrm{II}$ initiators eligible for inclusion in this analysis (Fig. I).

At each survey cycle following initiation, attainment of 12 events (milestones) related to either cigarette use (6 items) or to experiencing symptoms of nicotine dependence (6 items) was assessed. Of the 6 indicators of cigarette use, 5 indicators (first inhalation, monthly, weekly and daily smoking, and lifetime consumption of roo cigarettes) have been used in surveys on smoking in youth ${ }^{16,17}$ or in studies on initiation of smoking in youth. ${ }^{11-14}$ Lifetime consumption of Ioo cigarettes is commonly used to define the point at which smoking becomes established, and numerous studies only test cessation interventions among participants who have smoked at least Ioo cigarettes in their lifetime. ${ }^{3,4}$ The 6 milestones describing symptoms of nicotine dependence were the most frequently reported symptoms among novice smokers in an earlier analysis of this database $\mathrm{e}^{13}$ and are components of current diagnostic criteria for nicotine dependence in the $\mathrm{DSM}^{-\mathrm{IV}^{18}}$ and ICD-Io. ${ }^{19}$ The 6 milestones related to cigarette use included:

- Time of first inhalation: the survey date on which the participant first indicated ever taking cigarette smoke into his or her lungs for more than one puff

- Time of first whole cigarette: survey date on which the participant first reported ever smoking a whole cigarette (down to or close to the filter)

- Time of first monthly smoking: survey date on which the participant first responded "I smoke cigarettes once or a couple of times each month" in the self-perceived smoking status item

- Time of first weekly smoking: survey date on which the participant first responded "I smoke cigarettes once or a couple of times each week" in the self-perceived smoking status item

- Time of first daily smoking: survey date on which the participant first responded "I smoke every day" in the selfperceived smoking status item 
- Time of first lifetime consumption of Ioo cigarettes: survey date on which the participant first responded Yes to the question "Have you smoked Ioo or more whole cigarettes in your life? ( 100 cigarettes $=4$ packs of 25$)$ "

The 6 milestones related to symptoms of nicotine dependence were as follows:

- Time of first self-report of physical addiction: survey date on which the participant first responded "a little," "quite" or "very" to the question "How physically addicted to smoking cigarettes are you?" (Not at all; A little; Quite; Very)

- Time of first self-report of mental addiction: survey date on which the participant first responded "a little," "quite" or "very" to the question "How mentally addicted to smoking cigarettes are you?" (Not at all; A little; Quite; Very)

- Time of first symptom of tolerance: survey date on which the participant first responded "a bit true" or "very true" to the statement "Compared to when I first started smoking, I can smoke much more now before I start to feel nauseated or ill" (Not at all true; A bit true; Very true)

- Time of first craving: survey date on which the participant first responded Yes to the question "Do you ever have cravings to smoke cigarettes? (No; Yes)

- Time of first withdrawal symptom: survey date on which the participant first responded "rarely," "sometimes" or "often" to the question "Now think about the times when you have cut down or stopped using cigarettes or when you haven't been able to smoke for a long period (like most of the day). How often did you experience feeling a strong urge or need to smoke?" (Never; rarely; sometimes; often)

- Time of conversion to ICD-ro tobacco dependence: survey date on which the participant first met 3 or more of the 6 ICD-Io criteria for tobacco dependence. ${ }^{19}$ The development, as well as the psychometric properties, of our measure of ICD-Io tobacco dependence for adolescents has been described previously. ${ }^{20}$

Data on the first 2 milestones of nicotine-dependence symptoms - mental and physical addiction - were collected in all survey cycles from all respondents whether or not they reported smoking cigarettes. These items were developed based on earlier qualitative work in which adolescents were asked to describe their experiences of nicotine dependence and were able to distinguish between what they perceived to be mental and physical addiction. ${ }^{21}$ Data on the remaining 4 milestones were collected in each survey cycle, but only among subjects who reported smoking cigarettes in the 3 months preceding the questionnaire. The test-retest reliability and the convergent construct validity of several of these indicators were tested in earlier work and are uniformly excellent. ${ }^{20}$

We described the natural course of onset of cigarette use among the $3 \mathrm{II}$ initiators in terms of the cumulative probability of having attained the milestone of interest according to time in months from smoking initiation (first puff). Probabilities were computed using Kaplan-Meier survival analysis, which is

Table 1: Selected characteristics of study participants $(n=1293)$ at baseline according to smoking status

\begin{tabular}{|c|c|c|c|c|}
\hline \multirow[b]{2}{*}{ Characteristic } & \multicolumn{3}{|c|}{ Smoking status; \% of participants* } & \multirow[b]{2}{*}{$p$ value } \\
\hline & $\begin{array}{c}\text { Never smoked } \\
n=462\end{array}$ & $\begin{array}{l}\text { Initiated tobacco use } \\
\text { during follow-upt } \\
n=352\end{array}$ & $\begin{array}{l}\text { Baseline smokers } \\
\qquad n=479\end{array}$ & \\
\hline Age, yr, mean (SD) & $12.7(0.5)$ & $12.7(0.4)$ & $13.0(0.7)$ & $<0.001$ \\
\hline Male & 56.5 & 42.6 & 44.3 & $<0.001$ \\
\hline Language & & & & $<0.001$ \\
\hline English & 57.6 & 61.8 & 37.8 & \\
\hline French & 21.0 & 21.4 & 45.2 & \\
\hline English/French & 21.4 & 16.8 & 17.0 & \\
\hline Single-parent family & 6.1 & 8.8 & 13.6 & $<0.001$ \\
\hline No. of siblings, mean (SD) & $1.7(1.3)$ & $1.8(1.3)$ & $1.9(1.3)$ & 0.202 \\
\hline Spent entire life in Canada & 86.3 & 92.6 & 92.7 & 0.001 \\
\hline Father smokes & 18.2 & 21.6 & 36.7 & $<0.001$ \\
\hline Mother smokes & 15.2 & 18.8 & 38.6 & $<0.001$ \\
\hline Brother(s) smoke(s) & 6.1 & 7.1 & 16.3 & $<0.001$ \\
\hline Sister(s) smoke(s) & 4.3 & 5.7 & 12.7 & $<0.001$ \\
\hline Friends smoke & 14.8 & 28.1 & 67.3 & $<0.001$ \\
\hline Mother's education & & & & $<0.001$ \\
\hline Less than university & 48.0 & 49.2 & 41.5 & \\
\hline University & 33.7 & 36.7 & 21.3 & \\
\hline Missing & 18.3 & 14.2 & 37.3 & \\
\hline
\end{tabular}

*Unless stated otherwise.

†Forty-one who initiated tobacco use during follow-up are included in this table but were excluded from subsequent analysis because time of first puff could not be determined. 
the method of choice when the length of follow-up differs between respondents and when censoring occurs (i.e., when a participant is lost to follow-up or reaches the end of the study without having experienced the milestone). The Kaplan-Meier curve is interpreted as the cumulative probability that the milestone of interest has occurred by a particular point.

We repeated this analysis for 3 subgroups of initiators: the subjects who had inhaled into their lungs $(n=253)$, the subjects who smoked a whole cigarette $(n=2 \mathrm{I} 4)$ and the subjects who had experienced cravings $(n=\mathrm{I} 4 \mathrm{I})$. We hypothesized that the temporal sequence of, and time interval between, milestones might differ in these subgroups.

\section{Results}

Among the 3II participants included in our analysis who initiated cigarette smoking during follow-up (initiators), the median length of follow-up from collection of baseline data was 53 months (range 5-56 months), and the median length of follow-up from first puff was 3I months (range 0-54 months). The characteristics of the 3 II initiators were similar to those of participants who reported having never smoked; however, they differed from the characteristics of participants who reported current or past cigarette smoking at baseline (i.e., baseline smokers) in age, language spoken, family characteristics, and family members' and friends' smoking status. (Table I). The characteristics of the 4I initiators excluded from our analysis were similar to those of the 3 II included in the analysis.

\section{Attainment of milestones}

Table 2 summarizes the rate at which the initiators attained the 12 milestones investigated. The incidence rate of inhalation was relatively high (IO2 per Iooo person-months). It was substantially lower for smoking a whole cigarette and selfreported mental addiction, and substantially lower again for self-reported physical addiction, cravings, monthly smoking, withdrawal symptoms, tolerance, lifetime consumption of Ioo cigarettes, weekly smoking and daily smoking. The incidence rate of conversion to ICD-Io tobacco dependence was 7 per 1000 person-months. Incidence rates were notably higher among girls than among boys for most early milestones in the onset process. However, except for cravings and tolerance, the confidence intervals for all other milestones overlapped. Incidence rates among girls and boys were simi-

Table 2: Rate at which each milestone of smoking onset was attaind among adolescents who initiated cigarette smoking after study enrolment

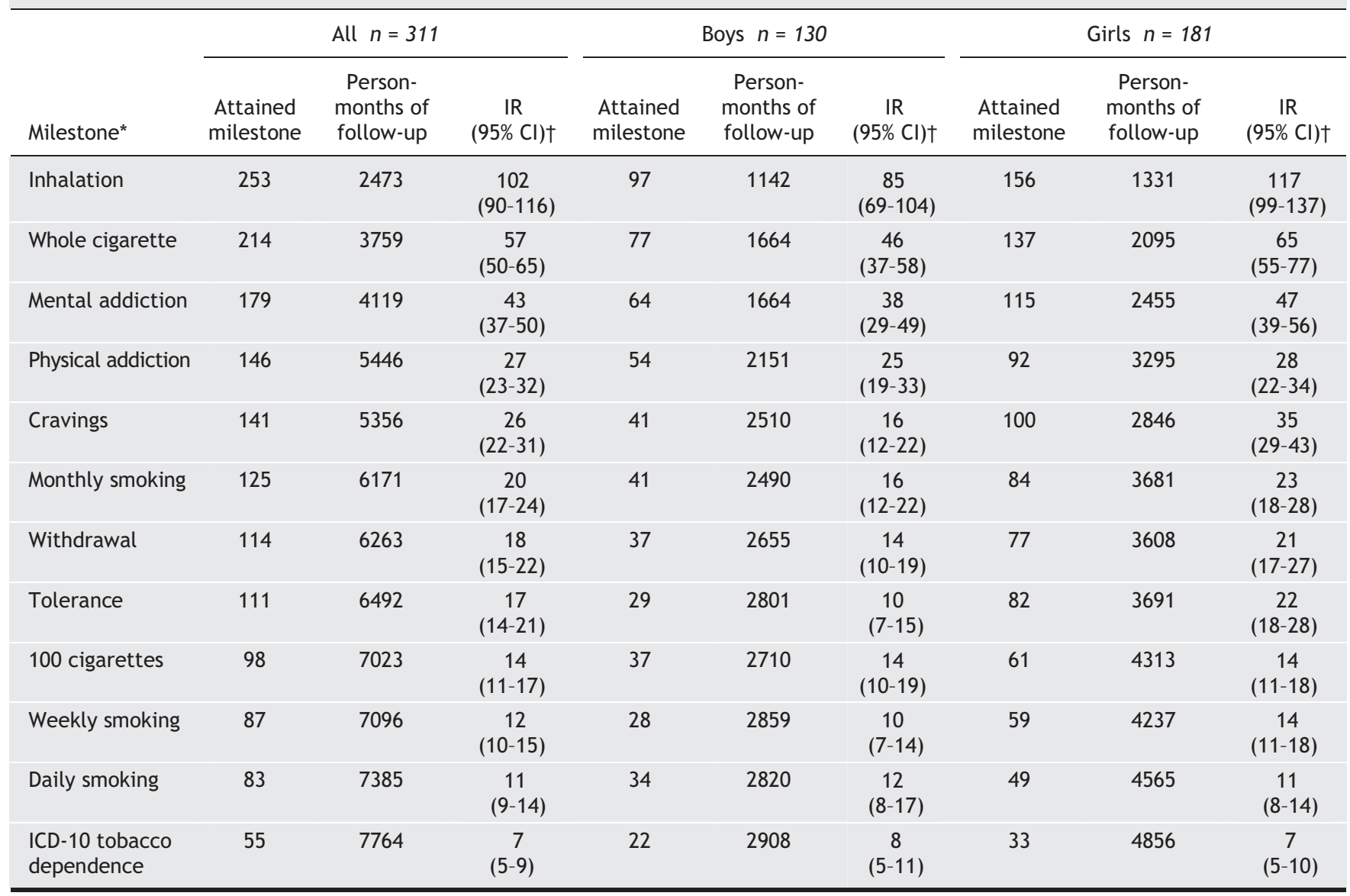

Note: $\mathrm{IR}$ = incidence rate, $\mathrm{Cl}=$ confidence interval.

*See Methods for description of milestones.

†incidence rate is the number of subjects who attained the milestone per 1000 person-months. The $95 \%$ confidence intervals were computed based on the Poisson distribution. 
lar for milestones that occurred late in the onset process, including lifetime consumption of Ioo cigarettes, daily smoking and conversion to ICD-ro tobacco dependence.

\section{Temporal sequence and time interval between milestones}

Fig. 2 depicts the cumulative probability of attaining each of the I2 milestones according to time from first puff. Except for the curve for inhalation, which leveled off at about 24 months after first puff, the cumulative probability of attaining most other milestones continued to increase over time. The cumulative probability of inhalation, smoking a whole cigarette and self-reported mental addiction increased sharply during the first 3 months after first puff; the rate of increase was slower thereafter. There was little overlap between the cumulative probability curves except for tight alignment and overlap between the curves for self-reported physical addiction and cravings, and between the curves for tolerance and withdrawal symptoms. The sharp increase in the probability of attaining several milestones at 54 months is difficult to interpret because of the small number of participants available for observation at 54 months. Overall, the figure suggests that, for most subjects, inhalation occurred after initiation, followed sequentially by smoking a whole cigarette, selfreported mental addiction, cravings, self-reported physical addiction, monthly smoking, withdrawal symptoms, tolerance, lifetime consumption of Ioo cigarettes, weekly smoking and daily smoking. Conversion to ICD-Io tobacco dependence was a relatively late and infrequent occurrence.

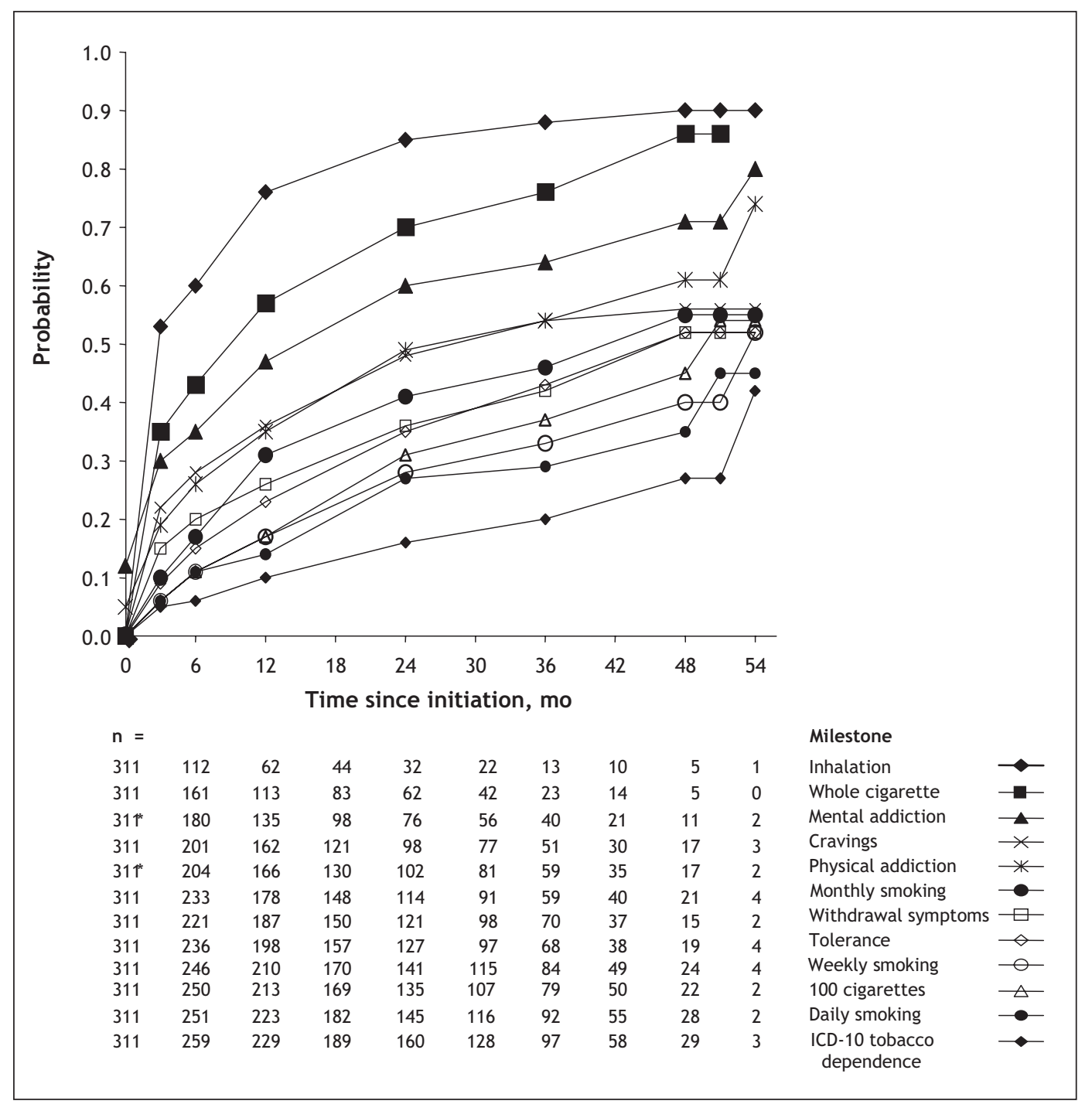

Fig 2: Cumulative probability of attaining milestones of onset of cigarette smoking from time since initiation among 311 participants who were nonsmokers at baseline and who initiated cigarette smoking during follow-up. See Methods for definitions of the milestones. ${ }^{*}$ Thirty-six subjects reported mental addiction and 15 reported physical addiction before initiation. These subjects were considered to be incident cases at baseline; they contributed zero person-months to the denominator in the computation of time at risk for selected milestone. 
Fig. 3 depicts the natural course of onset of cigarette smoking according to the milestones studied. More specifically, it gives the estimated number of months after first puff when the cumulative probability of attaining each milestone was $25 \%$. Inhalation and smoking a whole cigarette occurred rapidly within a few months; it took almost 9 months to attain the milestone of monthly smoking and about 20 months each to attain that of weekly smoking and a lifetime total of Ioo cigarettes, and an additional 4 months to attain the daily smoking milestone. Among the milestones related to nicotine dependence, mental addiction, cravings and physical addiction appeared rapidly (2-5 months after initiation). Withdrawal symptoms, tolerance and conversion to ICD-Io tobacco dependence took longer to develop (II-4I months after initiation).

The temporal sequence of the $\mathrm{I} 2$ milestones observed in the main analysis was similar across the subgroup analyses of participants who had inhaled into their lungs $(n=253)$ and those who had smoked a whole cigarette $(n=2 \mathrm{I} 4)$ (see online Appendix 3 and Appendix 4, available at www.cmaj.ca/cgi /content/full/175/3/255/DCI). In particular, symptoms of nicotine dependence, including cravings and self-reported mental and physical addiction, consistently preceded indicators of heavier smoking, including lifetime consumption of Ioo cigarettes, weekly smoking and daily smoking. The sequence was slightly different in the analysis that included only participants who had experienced cravings $(n=\mathrm{I} 4 \mathrm{I})$ (see online Appendix 5, available at www.cmaj.ca/cgi/content/full

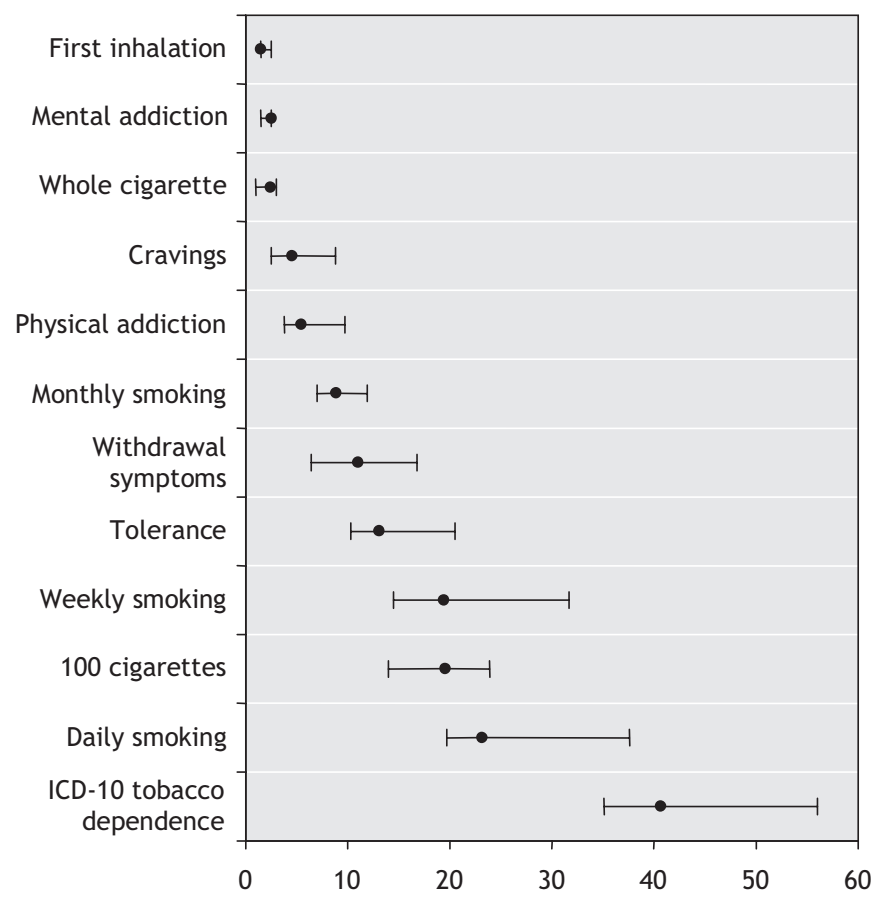

No. of months after initiation

Fig 3: Number of months after initiation of cigarette smoking (first puff) at which the probability of attaining each milestone is $25 \%$. Error bars represent $95 \%$ confidence intervals. (See Methods for definitions of the milestones.)
/175/3/255/DCI). Mental and physical addiction occurred first in this subgroup, followed by withdrawal symptoms and tolerance, and then by monthly smoking, consumption of 100 cigarettes, weekly smoking, daily smoking and finally conversion to ICD-Io tobacco dependence.

Overall, the probability of attaining each milestone was higher in each subgroup than in the total sample of initiators, which suggests that, as a person progresses through the milestones, the probability of attaining subsequent milestones increases. This was most prominent among subjects who reported cravings. Relative to all subjects and to those who reported inhalation or smoking a whole cigarette, initiators who reported cravings were at substantially increased risk of progressing to heavier smoking and to conversion to ICD-Io tobacco dependence during follow-up. For example, by 48 months, the cumulative probability of attaining daily smoking and of conversion to ICD-Io tobacco dependence was $68 \%$ and $49 \%$, respectively, among those who reported cravings. These probabilities were $35 \%$ and $27 \%$, respectively among all initiators, $54 \%$ and $33 \%$ among those who had inhaled into their lungs, and $64 \%$ and $37 \%$ among those who had smoked a whole cigarette, respectively.

\section{Interpretation}

This investigation documents the natural course of onset of cigarette use according to I2 milestones. After first puff, the participants who initiated cigarette smoking during followup (initiators) progressed rapidly to inhalation, and symptoms of nicotine dependence developed soon thereafter, well before weekly or daily smoking. Mental addiction was concomitant with smoking a whole cigarette and sometimes occurred even before initiation, possibly reflecting high susceptibility to initiating tobacco use. Cravings occurred early, and once present, there was a relatively high probability of attaining daily smoking and conversion to ICD-Io tobacco dependence. Withdrawal symptoms occurred shortly after monthly smoking, and tolerance was the last symptom reported. Incidence rates for milestones that appeared early after onset were higher among girls than among boys, but those for later milestones were similar across the sexes.

Challenging staged models of onset that do not incorporate early symptoms of nicotine dependence, ${ }^{6-8}$ several recent reports suggest that symptoms of nicotine dependence precede daily cigarette use and that they are prevalent among young smokers. ${ }^{11-14}$ In a 30-month follow-up in the DANDY (Development and Assessment of Nicotine Dependence in Youth) study, ${ }^{12}$ symptoms of nicotine dependence were reported by $40 \%$ of all participants who had ever used tobacco, and symptoms developed before daily smoking in $70 \%$ of these subjects. The median latency to development of dependence symptoms was 54 days from monthly smoking (2I for girls, 183 for boys). "Strong cravings" and "real need for a cigarette" were the 2 earliest, and most frequently reported, symptoms, with median latencies of I4I and I79 days, respectively. "Strong cravings" were reported by $28 \%$ of subjects and "real need" by $31 \%$. The need or urge to smoke on trying to stop (a withdrawal symptom), and feeling addicted, which 
were each reported by about $25 \%$ of all youth who had smoked, appeared 202 and 215 days after monthly smoking. In the McGill University Study on the Natural History of Nicotine Dependence in Teens, the proportion of subjects who reported conversion to ICD-Io tobacco dependence at baseline increased from $0 \%$ and $3 \%$ among those who tried smoking and sporadic smokers, to $5 \%, 19 \%$ and $66 \%$ among monthly, weekly and daily smokers, respectively. Girls reported more symptoms of nicotine dependence than did boys in all subgroups of smokers. ${ }^{13}$ Overall, $57 \%, 4 \mathrm{I} \%, 44 \%$ and $33 \%$ of monthly smokers reported cravings, strong urge to smoke on stopping, mental addiction and physical addiction, respectively; similarly, $93 \%, 83 \%, 82 \%$ and $89 \%$ of daily smokers reported these symptoms. ${ }^{13}$

Several limitations may affect the interpretation of our results. We studied adolescents who initiated cigarette use during secondary school, but the natural course of onset may differ for those who initiate smoking earlier or later in life. The sample was too small for sex-specific analyses. Data were based on self-reports; however, recall of cigarette use over 3 months is very good, ${ }^{15}$ and our measures of symptoms of nicotine dependence are reliable, internally consistent and demonstrate convergent construct validity. ${ }^{17}$

In summary, our data suggest that a person's first puff may represent the beginning of a process that leads rapidly to symptoms of nicotine dependence and escalating cigarette use in some young smokers. Novice smokers may not recognize the symptoms they experience as related to nicotine dependence, and consequently they may view tobacco control messages as irrelevant. Young people, their parents and health professionals must be made aware that symptoms of nicotine dependence can manifest long before regular smoking and that, once cravings are experienced, the likelihood of progression to daily use and tobacco dependence is greatly increased. This information should be incorporated into interventions to encourage and support novice smokers to stop smoking, and to provide help for those experiencing difficulty quitting because of symptoms of nicotine dependence.

This article has been peer reviewed.

From the Department of Epidemiology, Biostatistics and Occupational Health, McGill University (O'Loughlin, Bancej), and the Agence de santé et des services sociaux, Direction de santé publique, Montréal, Que. (Gervais, Meshefedjian), and the Institut national de santé publique du Québec, Québec, Que. (Tremblay)

Competing interests: None declared.

Contributors: André Gervais coordinated the analysis and writing team, contributed to the analysis and interpretation of data, drafted the article and completed the final version of the manuscript. Jennifer O'Loughlin designed the study, obtained the funding, developed the survey instruments, super- vised data collection, contributed to the analysis and interpretation of data, and contributed to the writing of the manuscript. Christina Bancej reviewed the literature and contributed to data interpretation and preparation of the manuscript. Garbis Meshefedjian performed data analysis and contributed to data interpretation. Michèle Tremblay contributed to planning the data analysis and contributed to the data interpretation. All of the authors reviewed the manuscript critically for important intellectual content and approved the final version to be published.

\section{REFERENCES}

I. Thomas R. School-based programmes for preventing smoking [review]. Cochrane Database Syst Rev 2002;(4):CDoor293.

2. Sowden A, Arblaster L, Stead L. Community interventions for preventing smoking in young people [review]. Cochrane Database Syst Rev 2003;(I):CDoor29I.

3. Sussman S. Effects of sixty-six adolescent tobacco use cessation trials and seventeen prospective studies of self-initiated quitting. Tobacco Induced Diseases 2002;I:35-8I.

4. McDonald P, Colwell B, Backinger CL, et al. Better practices for youth tobacco cessation: evidence of review panel. Am J Health Behav 2003;27(Suppl 2):Si44-58.

5. Renaud L, O'Loughlin J, Dery V. The St-Louis du Parc heart health project: a critical analysis of the reverse effects on smoking. Tob Control 2003;12:302-9.

6. Mayhew KP, Flay BR, Mott JA. Stages in the development of adolescent smoking. Drug Alcohol Depend 2000;59:S6I-8I.

7. Flay BR. Youth tobacco use: risk patterns, and control. In: Slade J, Orleans CT, editors. Nicotine addiction: principles and management. New York: Oxford University Press; 1993. p. 365-84.

8. Preventing tobacco use among young people: a report of the Surgeon General. Atlanta: US Department of Health and Human Services, Public Health Service, US Centers for Disease Control and Prevention, National Center for Chronic Disease Prevention and Health Promotion, Office on Smoking and Health; I994.

9. Lerman $\mathrm{C}$, Berrettini $\mathrm{W}$. Elucidating the role of genetic factors in smoking behavior and nicotine dependence. Am J Med Genet B 2003; II 8(B):48-54

Io. Breslau N, Fenn N, Peterson E. Early smoking initiation and nicotine dependence in a cohort of young adults. Drug Alcohol Depend I993;33:I29-37.

II. DiFranza JR, Rigotti NA, McNeill AD, et al. Initial symptoms of nicotine dependence in adolescents. Tob Control 2000;9:313-9.

I2. DiFranza JR, Savageau JA, Rigotti NA, et al. Development of symptoms of tobacco dependence in youths: 30 month follow up data from the DANDY study. Tob Control 2002; II: 228-35.

I3. O'Loughlin J, DiFranza J, Tyndale R, et al. Nicotine dependence symptoms are associated with smoking frequency in adolescents. Am J Prev Med 2003;25:219-25.

I4. Wellman RJ, DiFranza JR, Savageau JA, et al. Short term patterns of early smoking acquisition. Tob Control 2004;13:25I-7.

I5. Eppel A. O'loughlin J, Paradis G, Platt R. Reliability of self-reports of cigarette use in novice smokers. Addict Behav. In Press.

I6. Choi WS, Pierce JP, Gilpin EA. Which adolescent experimenters progress to established smoking in the United States. Am J Prev Med I997;13:385-9I.

I7. Pierce JP, Gilpin E. How long will today's new adolescent smoker be addicted to cigarettes? Am J Public Health i996;86:253-6.

I8. American Psychiatric Association. Diagnostic and statistical manual of mental dis-

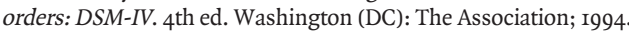

I9. World Health Organization (WHO). International Statistical Classification of Diseases and Related Health Problems, Ioth revision. Geneva: WHO, I992.

20. O'Loughlin J, Tarasuk J, DiFranza JR, et al. Reliability of selected measures of nicotine dependence among adolescents. Ann Epidemiol 2002;12:353-62.

2I. O'Loughlin J, Kishchuk N, DiFranza JR, et al. The hardest thing is the habit: a qualitative investigation of adolescent smokers' experience of nicotine dependence. Nicotine Tob Res 2002;4:201-9.

Correspondence to: Dr. Jennifer O'Loughlin, Department of Epidemiology, Biostatistics and Occupational Health, McGill University, ro2o Pine Ave. W, Montréal QC $\mathrm{H}_{3} \mathrm{~A}$ IA2; fax 514 398-45or; jennifer.oloughlin@mcgill.ca 